\title{
Inflammatory aneurysm of the ascending thoracic aorta
}

\author{
Matthias Roth, MD, ${ }^{a}$ Peter Lemke, MD, ${ }^{a}$ Rainer M. Bohle, MD, ${ }^{b}$ Wolf P. Klövekorn, MD, and Erwin P. Bauer, MD, \\ Bad Nauheim and Giessen, Germany
}

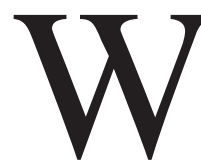

alker and colleagues ${ }^{1}$ were the first to define the term "inflammatory aneurysm." They reported 19 cases and found that these aneurysms were nonbacterial special types of atherosclerotic aneurysms. Inflammatory aneurysms constitute approximately $5 \%$ of all infrarenal abdominal aortic aneurysms. ${ }^{2}$ However, location of these aneurysms in the ascending thoracic aorta is extremely uncommon. ${ }^{3}$ Connery and colleagues ${ }^{4}$ first described an isolated inflammatory aneurysm in the ascending thoracic aorta. Typical histologic examination shows signs of chronic inflammation in the

From the Department of Thoracic and Cardiovascular Surgery, Kerckhoff Clinic Foundation, ${ }^{\mathrm{a}}$ Bad Nauheim, and the Department of Pathology, Justus Liebig University, ${ }^{\mathrm{b}}$ Giessen, Germany.

Received for publication Sept 14, 2001; accepted for publication Oct 23, 2001.

Address for reprints: Matthias Roth, MD, Department of Thoracic and Cardiovascular Surgery, Kerckhoff Clinic Foundation, 61231 Bad Nauheim, Benekestr 2-8, Germany (E-mail: Matthias.Roth@kerckhoff.med. uni-giessen.de).

J Thorac Cardiovasc Surg 2002;123:822-4

Copyright $\odot 2002$ by The American Association for Thoracic Surgery

$0022-5223 / 2002 \$ 35.00+0 \quad \mathbf{1 2 / 5 4 / 1 2 1 2 9 1}$

doi: $10.1067 / \mathrm{mtc} .2002 .121291$ adventitia with a marked lymphoplasmacytic cell infiltrate and granulation or fibrous tissue proliferation. ${ }^{5}$

\section{Clinical Summary}

A 65-year-old woman underwent neurologic rehabilitation for endogenous depression. During that stay, sudden asystole occurred, and cardiopulmonary resuscitation was necessary. Transesophageal echocardiography showed a dilated ascending aorta with a diameter of 43 to $45 \mathrm{~mm}$. A false lumen was suspected that was filled by a hematoma. However, a typical membrane was not observed. Angiography revealed normal left ventricular function, mild aortic insufficiency, and dilatation of the ascending aorta (Figure 1). A dissection membrane was not found. T1- and T2weighted magnetic resonance imaging showed an ascending aorta with a diameter of $45 \mathrm{~mm}$. The entire wall of the ascending aorta was markedly thickened (10 mm; Figure 1, inset). Chronic type A dissection was diagnosed, and an operation was subsequently performed. Intraoperatively, a chronic inflammatory mass adherent to the superior vena cava and pulmonary artery was seen. Clamping of the aorta was impossible because of wall thickness and severe adhesions. Cardiopulmonary bypass was instituted, and the patient was cooled to $24^{\circ} \mathrm{C}$. Circulatory arrest and retrograde cerebral perfusion were commenced, and the aneurysm was longitudinally opened. The wall of the ascending aorta was thickened and white colored (Figure 2, inset). A dissection membrane was 


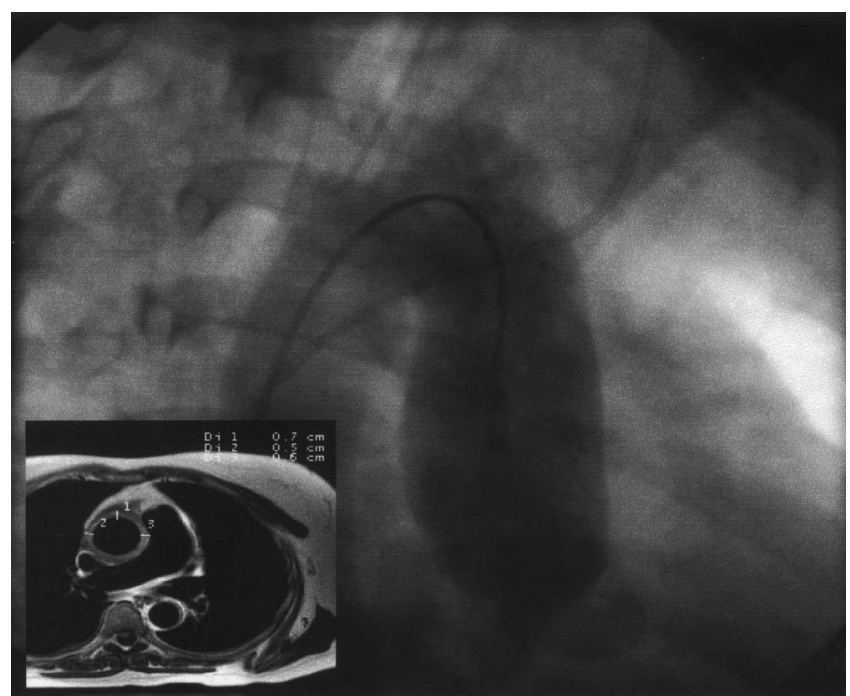

Figure 1. Preoperative angiogram of the ascending thoracic aorta (inset) and magnetic resonance imaging showing the thickened wall of the ascending aorta.

not found (Figure 2). The sinuses of Valsalva and the aortic valve were not involved in the pathologic process. The ascending aorta was replaced with a 24-mm Dacron graft (Vascutek; Inchinnan, Renfrewshire, Scotland). The postoperative course was uneventful, and the patient was discharged on the twelfth postoperative day.

Macroscopic evaluation of the aortic specimen showed a wall thickness of up to $12 \mathrm{~mm}$. Microscopically, the adventitia was impressively thickened by fibrotic tissue and was infiltrated by plasma cells and lymphocytes. The media showed minimal fibrotic and segmental infiltrates with lymphocytes and plasma cells (Figure 3). There was no serologic evidence of syphilis. The intima contained moderate fibroatheromatous lesions.

\section{Discussion}

Inflammatory aneurysms located in the thoracic aorta are rare in contrast to those of the abdominal aorta. Crawford and colleagues 6 described 5 cases in the descending aorta and aortic arch. Two cases of isolated inflammatory aneurysm of the ascending aorta were described by Connery and colleagues ${ }^{4}$ and Girardi and Coselli. ${ }^{3}$ To our knowledge, these are the only reports dealing with this pathologic condition. The cause of inflammatory aneurysms is still unclear. It may be related to a process known as chronic periarteritis, idiopathic mediastinal fibrosis, and perianeurysmal retroperitoneal fibrosis. It is believed that the inflammatory response in these disorders may be due to an autoimmune response to a component of atherosclerotic plaque. ${ }^{4}$ Some authors discuss an autoaggressive process as a possible cause of inflammatory aneurysm. ${ }^{6}$ Pathologic anatomy of these aneurysms is similar to inflammatory aneurysms of the abdominal aorta. The vascular wall is markedly thickened and densely adherent to the surrounding structures. On microscopy, the adventitia and periadventitial tissue are thickened by fibrotic tissue and infiltrated by clusters of lymphocytes and plasma cells. . $^{3,7}$ These microscopic findings correspond to our histologic examination. Because of the lack of ele-

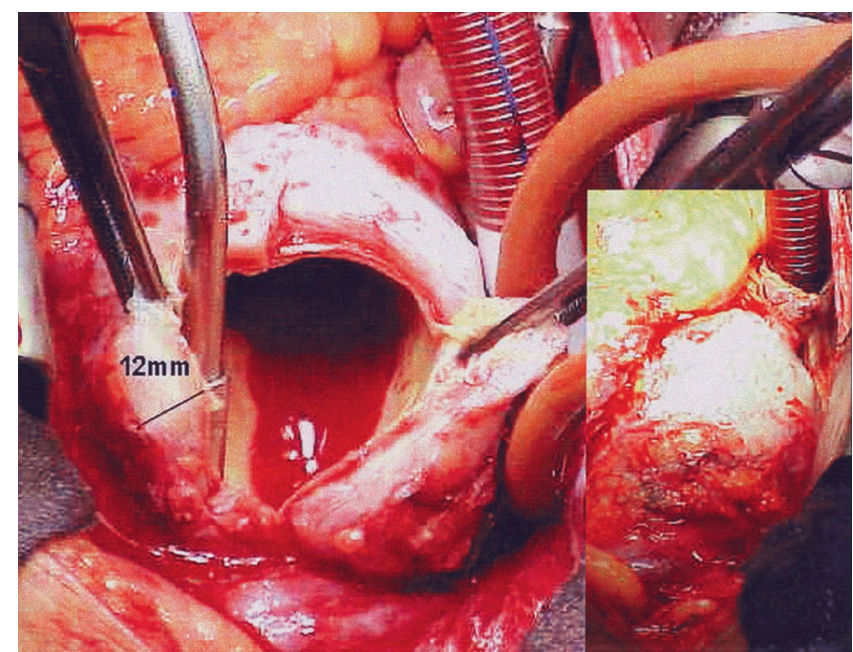

Figure 2. Intraoperative image of the incised aortic wall (inset) and macroscopic aspect of the ascending thoracic aorta.

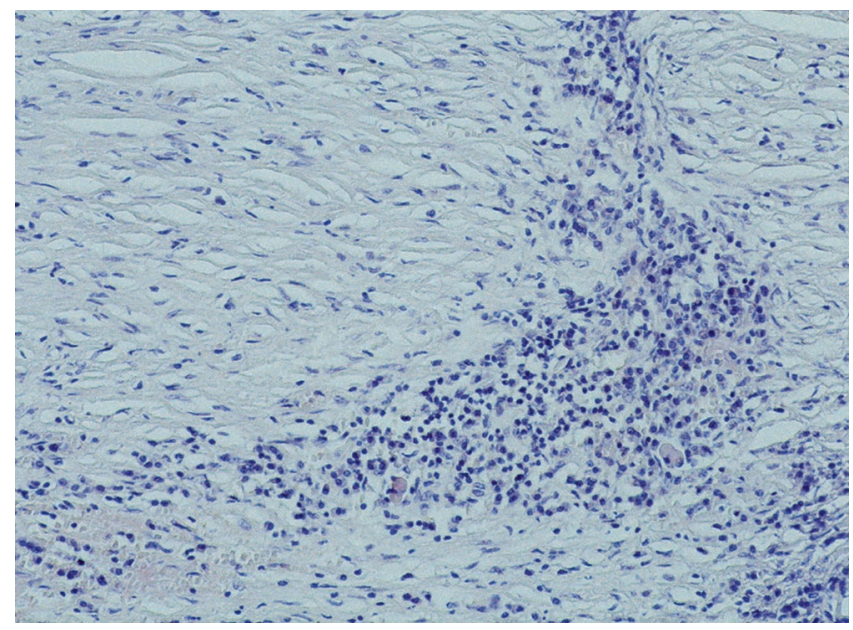

Figure 3. Histologic view of the aortic wall showing chronic fibrosing periaortitis. Adventitia of the aortic wall with plasma cell-rich (immunohistology: $\kappa$ light chain and light chain positive) round-cell infiltrate and severe adventitial fibrosis. (Original magnification $\times 40$.)

vated inflammatory laboratory parameters, negative syphilitic serology, and the absence of giant cells, giant cell-associated medial necrosis, microgummas, and other granulomatous diseases (eg, Takayasu aortitis and giant cell aortitis) are ruled out in our patient. As described by other authors, preoperative diagnosis is a major problem because neither transthoracic and transesophageal echocardiography nor computed tomography and magnetic resonance imaging could identify the true pathologic condition. ${ }^{8}$ Contrast enhancement of a thickened aortic wall raises the suspicion of an inflammatory aneurysm. Nevertheless, aortic dissection with a thrombosed false lumen is a differential diagnosis.

We used profound hypothermic and circulatory arrest for 2 reasons. First, clamping of the inflammatory aorta was dangerous 
because the aortic wall was markedly thickened; second, it was impossible to dissect adjacent structures, such as the superior vena cava and pulmonary artery, because of severe adhesions. The same surgical technique was used by Goldstone and colleagues, ${ }^{2}$ Girardi and Coselli, ${ }^{3}$ and Künzli and coworkers. ${ }^{8}$

The natural progress of inflammatory aneurysms of the ascending thoracic aorta is unknown. Potential complications are rupture of the diseased aortic wall or superior vena cava syndrome. If rapid enlargement of the ascending aorta or severe chest pain occurs, replacement of the ascending thoracic aorta is recommended.

We thank Dr W. Hort, Düsseldorf, for reviewing the case.

\section{References}

1. Walker DI, Bloor K, Williams G, Gillie I. Inflammatory aneurysms of the abdominal aorta. Br J Surg. 1972;59:609-14.
2. Goldstone J, Malone JM, Moore WS. Inflammatory aneurysms of the abdominal aorta. Surgery. 1978;83:425-30.

3. Girardi LN, Coselli JS. Inflammatory aneurysm of the ascending aorta and aortic arch. Ann Thorac Surg. 1997;64:251-3.

4. Connery CP, Descalzi ME, Kirshner R. Inflammatory aneurysm of the ascending aorta: an unreported entity. J Cardiovasc Surg. 1994;35: 33-45.

5. Rose AG. Aneurysms of the abdominal aorta. In: Bloom S, Lie T, Silver M, editors. Diagnostic criteria for cardiovascular pathology: acquired diseases. Philadelphia: Lippincott-Raven; 1997. p. 153-4.

6. Crawford JL, Safi H, Stowe CL, Hallmann CH, Crawford ES. Inflammatory aneurysms of the aorta. J Vasc Surg. 1985;2:113-24.

7. Iha K, Ikemura R, Horikawa Y, Akasaki M, Kuniyoshi Y, Koja K. Surgical treatment of multiple inflammatory aortic aneurysms of the aortic arch and thoracoabdominal aorta. Jpn J Thorac Cardiovasc Surg. 2000;48:509-11.

8. Künzli A, von Segesser LK, Vogt PR, Spahn DR, Schneider J, Jenni $\mathrm{R}$, et al. Inflammatory aneurysm of the ascending aorta. Ann Thorac Surg. 1998;65:1132-3. 